\title{
OBITUARY
}

\section{FRANCIS BERNARD CHAVASSE}

So frequent in war time becomes the news of sudden extinction of life that its poignancy is often blunted and leaves but a passing regret; but when the loss involves one in the prime of life, having accomplished much, but with his best work still to come, it assumes the form of a tragedy.

Bernard Chavasse was in his fifty-third year when he lost his life in July in a motoring accident. "Men must endure their going hence, even as their coming hither : ripeness is all."

Educated at Oxford where he took first class honours in Natural Science and obtained all the scholarships of his year in his medical course, and at Liverpool he went straight into the R.A.M.C. after qualification. The war over, attracted by ophthalmology, he prepared himself for his career by an intensive study of physiology and medicine. In his work as Lecturer in Ophthalmology in the University of Liverpool and in his teaching of students, the importance of a thorough knowledge of these subjects in their relation to general diseases was always a favourite theme. He took the M.R.C.P., the D.M. and D.O. of Oxford, went through the usual Moorfields and other appointments and returned to Liverpool, the home of his boyhood. He entered into partnership with Edgar Stevenson, and after the latter's retirement carried on this old established and successful practice.

It cannot be said that Chavasse owed his success to being the son of the late Bishop of Liverpool, nor to the brilliant war record of his brothers and himself, yet heredity undoubtedly played its part. The outspoken uncompromising faith of his father showed itself in the son by his condemnation of any ideas, methods or practices with which his reason differed-even his slow, emphatic, rather didactic method of speaking was his father's. There were four sons, elder and younger twins. Of the elder-one gained the V.C. with bar (the latter posthumously), an achievement almost without precedent in medical records, the other, now himself a Bishop, the M.C. Chavasse's own M.C. was won by a particularly gallant effort to save the life of his twin reported to be lying wounded in No-Man's-Land. For two nights he crawled about searching over a wide area, but in vain. If one imagines the horrors it entailed, it must have been an experience which left its mark throughout his life. Incidentally it will be remembered that a splint he devised for fractured femur while a medical officer has been used in France in the present war.

Chavasse was a frequent contributor to the proceedings of the Ophthalmological Society, as well as those of the North of England 


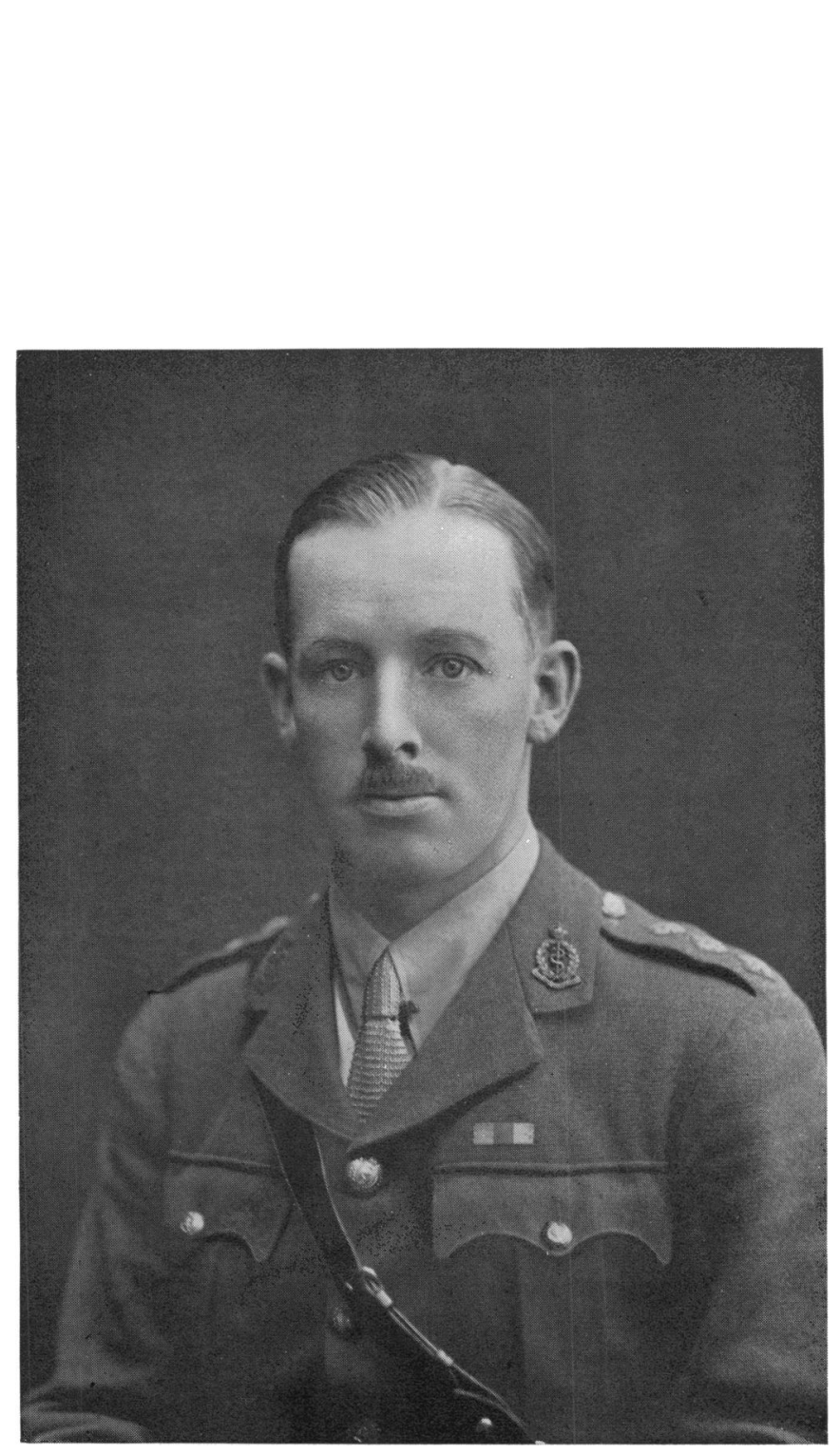

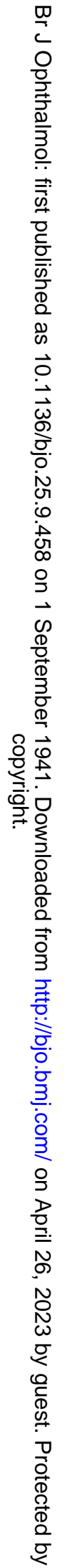

FRANCIS BERNARD CHAVASSE

(from photo taken during the last war) 
Society and the Oxford Congress. His papers were marked by originality, and his command of well-chosen phrases with an occasional flash of humour enhanced his interventions in debate. In later years it was the subject of squint which almost exclusively claimed his researches, and to which his main output in literature was devoted. His name will be long remembered for the re-writing of 'Worth's Squint,' in which his new ideas on its physiology and pathology have cast a fresh light on the whole subject. Though his methods of expressing himself may have been provocative, the work, like that of its predecessor, may well become a classic. His views on the value of orthoptic training illustrate his fearless attitude in attacking a system which he considered a help to diagnosis rather than to treatment. His own modifications of operations form an interesting part of the book and represent the toil of years-he had made himself into an excellent operator. Had he lived, he might, in subsequent editions have simplified its phraseology for the benefit of his less scientific readers. His chapter on the development and pathology of binocular reactions in Ridley and Sorsby's book also shows much originality.

Latterly his researches and writing claimed the greater part of his spare time. For this he gave up a great deal of his social life and practically all his recreation. Even yachting, which was at one time his great relaxation, was almost neglected. What one might call a "hobby" was his devotion to the well being of the Liverpool Eye and Ear Infirmary. Only his colleagues could appreciate what he did for the hospital - as Secretary of the Medical Board which he represented on numerous local committees, in raising money from his patients and friends for the equipment of the new Out Patient Department, the establishment of an orthoptic department with his own methods and training, and his interest in the internal administration of the hospital. He was a loyal colleague whose loss to the hospital is irreparable, and his active and scientific brain would undoubtedly have further enriched ophthalmology had he lived his normal span. To his wife and three children we dare do no more than to express our sympathy in their bereavement.

T. L. de C.

We have received the following lines from an old friend who wishes to remain anonymous :

Thoughts about Chavasse on attending his Memorial Service, July 12, 1941.

This simple but impressive Memorial Service took place in the Protestant Cathedral (where his Father had once reigned as Bishop) on July 12,1941 , at noon.

I do not think that the mystery and unexpectedness of Death have often been brought more acutely home to mourning colleagues. 
Here was a man cut off by the Great Reaper when just approaching the full harvest of his maturity.

Bernard Chavasse was indeed a Master in Ophthalmology and altho' the subject of squint was the dream child of his brain, such was his virile character, crescive in its faculty, that one could hardly set limits to his future progress and adventure along other avenues of that delightfully interesting subject of Ophthalmology.

He was ever growing in curiosity, zeal and endeavour.-'a man's grasp should be beyond his reach-else what's a Heaven for.' He dared valourously; indeed to his character might be well ascribed those resounding lines of the Poet Browning :-

One who never tuined his back
But marched breast forward
Never doubted clouds would break,
Never dreamed, though right were worsted
Wrong would triumph.
Held we fall to rise, are baffled to fight better,
Sleep to wake.

One who never tuined his back

But marche

Never doubted clouds would break,

Never dreamed, though right were worsted

Wrong would triumph.

Sleep to wake.

\section{NOTES}

War and Ophthalmic Literature

In the June number of the Amer. Jl. of Ophthal., the Editor, Derrick Vail, in a leading article comments on the hardship caused to scientific journals of all sorts by the disruptive effects of war on the exchange of medical ideas and literature. He notes that the abstract section of his journal has suffered severely by the hindrance of war, and pays a very kindly tribute, for which we wish to thank him sincerely, to the Brit. Jl. of Ophthal., which still reaches him regularly, though it is "somewhat reduced in size." All those concerned in the production of the British Journal share his admiration for those contributors, who, though "interrupted by daily bombing and mental distress, yet find time to record their observations " and write papers to keep the British ophthalmic flag flying, and the editorial department is the first to acknowledge the work of those men which has made their share in the production of the journal, comparatively speaking, an easy one.

Ophthalmological

Society of the

United Kingdom

THE Annual Congress of the Ophthalmological Society will be held, circumstances permitting, in Cambridge on September 4 and 5, 1941.

The subject for discussion will be "Ocular Injuries resulting from the War." Openers will be 1)r. O. M. Duthie (Manchester) and Dr. S. Zuckerman (Oxford). 